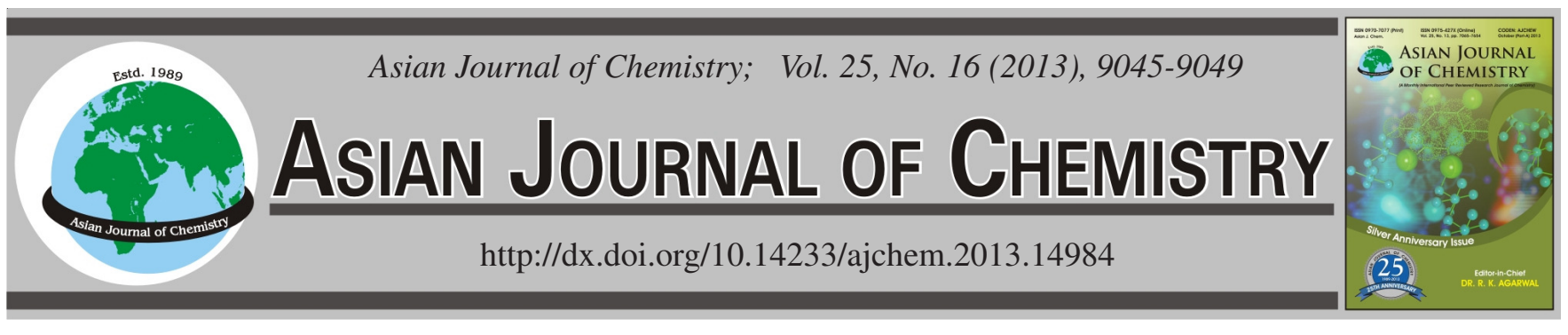

\title{
Optical Properties of Nano-Crystalline Cerium Dioxide Synthesized by Single Step Aqueous Citrate-Nitrate Gel Combustion Method
}

\author{
Divinah Manoharan ${ }^{*}$ and K. Vishista
}

Department of Physics, Anna University, Chennai-600 025, India

*Corresponding author: Tel: +91 44 22358689; E-mail: divinah@gmail.com

\begin{abstract}
The present study explores the versatility of aqueous combustion method for preparing powders of varying characteristics suitable for optical application. Combustion synthesis was carried with fuel lean composition which yields crystalline ceria nanoparticles instantaneously. Phase purity of the nanocrystals was confirmed by X-ray diffraction and the average crystallite size was determined to be $5 \mathrm{~nm}$. The surface morphology was analyzed by scanning electron microscopy. The spherical particle size obtained from the transmission electron microscopy was in the range of 4-5 $\mathrm{nm}$. The selected area electron diffraction pattern was completely indexed with the cubic fluorite structure of $\mathrm{CeO}_{2}$. Purity of the sample was confirmed by energy-dispersive X-ray spectroscopy and Fourier-transform infrared spectroscopic analysis. The energy band gap of $3.4 \mathrm{eV}$ was determined from the ultra-violet diffuse reflectance spectra using Kubelka-Munk function and UV-Visible absorption spectra using Tauc plot. The nanoparticles exhibited strong UV absorption and room temperature photoluminescence.
\end{abstract}

Key Words: Nano-crystalline, Aqueous combustion, Photoluminescence, Citrate-nitrate gel, Kubelka-Munk function, Tauc plot.

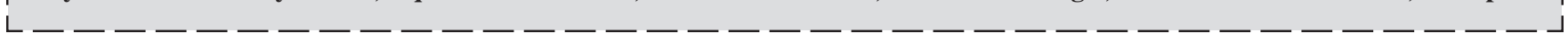

\section{INTRODUCTION}

Rare earth compounds due to their special electronic configuration encompass wide applications. Nano-structured rare earth compounds, show explicit optical, mechanical, magnetic, chemical activity, chemical reactivity, catalytic and biomedical properties owing to high surface to volume ratio and quantum size effect ${ }^{1}$. Ceria nanoparticles is commonly believed to exhibit appreciable oxidation activity, exclusive UV absorbing ability, fair thermal stability, high hardness and reactivity as catalyst ${ }^{2,3}$. The cerium dioxides have been extensively used as glass polishing material ${ }^{4,5}$, oxygen ion conductor in solid oxide fuel cells (SOFC) ${ }^{6}$, gas sensor ${ }^{7}, \mathrm{UV}$ absorbent ${ }^{8}$, catalytic support or promoter for automotive exhaust gas conversion reaction $^{9-11}$. It is used as a minor additive in silicon nitride $^{12}$ and it is also used as an additive to enhance the toughness of sintered zirconia ${ }^{13}$. All these applications demand highpurity cerium oxide in the finest-particulate form.

Combustion synthesis ${ }^{14-18}$ is swiftly up-coming as one of the most efficient methods for the preparation of a wide variety of materials, ranging from non-oxides to simple and complex oxides due to the self-purifying feature because of the high temperatures involved and the possibility of obtaining products in the desired size and shape. An aqueous solution of a redox system constituted by the nitrate ions of the metal precursor, acting as oxidizer and a fuel like urea, glycine, citric acid ${ }^{19}$ or many others ${ }^{16}$ is heated upto moderate temperatures and upon dehydration, the strongly exothermic redox reaction develops, which is generally self-sustaining and provides the energy for the formation of the oxide. The present paper is intended to investigate the optical properties of nanocrystalline cerium dioxide synthesized by a fast, easy, cost effective and simple aqueous citric-nitrate gel combustion method ${ }^{20}$.

\section{EXPERIMENTAL}

As per the propellant chemistry, in combustion reaction the ratio of fuel and oxidant is fixed in such a way that the net reducing valency of the fuel equals to the net oxidizing valency of the oxidant ${ }^{21}$. AR grade cerium nitrate hexahydrate $\left[\mathrm{Ce}\left(\mathrm{NO}_{3}\right)_{3} \cdot 6 \mathrm{H}_{2} \mathrm{O}\right]$ and citric acid monohydrate $\left(\mathrm{C}_{6} \mathrm{H}_{8} \mathrm{O}_{7} \cdot \mathrm{H}_{2} \mathrm{O}\right)$ (fuel to oxidant ratio $\varphi=0.7$ ) were mixed in a minimum volume of de-ionized water to obtain transparent aqueous solutions. Citric acid is a strong complexing agent and forms stable gel in nitrate solutions. Adjusting the $\mathrm{pH}$, by addition of liquid ammonia results in networking of the precursor molecules by enforced hydrolysis and thereby, justifying the process as gel combustion method. Ammonia solution was added drop wise to adjust the $\mathrm{pH}$ to $\mathrm{ca}$. 2. The solution was heated on a laboratory hot plate. With evaporation of water the solution temperature increased and a transparent gel was formed. Citric acid has 
three carboxylic and one hydroxyl group for coordinating the metal ions, which facilitate the formation of viscous gel on heating $^{22}$. Heating was continued till the start of gel combustion reaction which resulted in the formation of light yellowish white powder. No black particle was observed in the combustion synthesized powder indicating nearly complete removal of carbon. The obtained ceria nano powders were ground finely with agate mortar and pestle.

\section{RESULTS AND DISCUSSION}

Structural characterization: The typical XRD pattern of the as-synthesized nano- $\mathrm{CeO}_{2}$ is shown in Fig. 1. All the peaks have been indexed to the face centered cubic structure (fluorite type) of $\mathrm{CeO}_{2}$ (space group $\mathrm{Fm} 3 \mathrm{~m}$ ) with lattice parameter, $\mathrm{a}=5.4113 \AA$ (standard data JCPDS 34-0394). Moreover no additional peaks corresponding to any new phase were observed indicating high purity of the prepared samples. The crystallite sizes was estimated to be $5 \mathrm{~nm}$ from the line broadening of the peak due to (111) plane by using Scherer equation ${ }^{23}$. Fig. 2 shows the FTIR spectra of the pure ceria nanoparticles. The large absorption band located at around $547 \mathrm{~cm}^{-1}$ can be attributed to the (Ce-O-O) stretching mode of vibration thereby confirming the formation of $\mathrm{CeO}_{2}{ }^{24-28}$. The extremely small bands located at around 1030, 840 and $719 \mathrm{~cm}^{-1}$ corresponds to the $\mathrm{CO}_{2}$ asymmetric stretching vibration, $\mathrm{CO}_{3}{ }^{2-}$ bending vibration and $\mathrm{C}-\mathrm{O}$ stretching vibration, respectively ${ }^{29}$. These bands are linked to the presence of atmospheric $\mathrm{CO}_{2}$ adsorbed on the metallic cation ${ }^{30}$ and the formation of "carbonate-like" species on the particle surfaces ${ }^{26}$. The band located around $1374 \mathrm{~cm}^{-1}$ is attributed to carbonate species vibrations ${ }^{26,29}$. The band located at around $1600 \mathrm{~cm}^{-1}$ is attributed to the $\mathrm{H}-\mathrm{O}-\mathrm{H}$ bending vibration ${ }^{30}$. Ceria has the ability to absorb water molecules from the surrounding environment; thus, the strong peak at $3427 \mathrm{~cm}^{-1}$ corresponds to the physically adsorbed water $(\mathrm{O}-\mathrm{H})$ on the samples ${ }^{31,32}$.

Morphological and compositional characterization: The SEM images shown in Fig. 3(a) and (b) reveal the surface morphology of pure $\mathrm{CeO}_{2}$ nanoparticles. The combustion synthesized powders are porous spongy agglomerates of primary particles with voluminous foamy structure. The bonds between the particles in this foamy structure appear to be

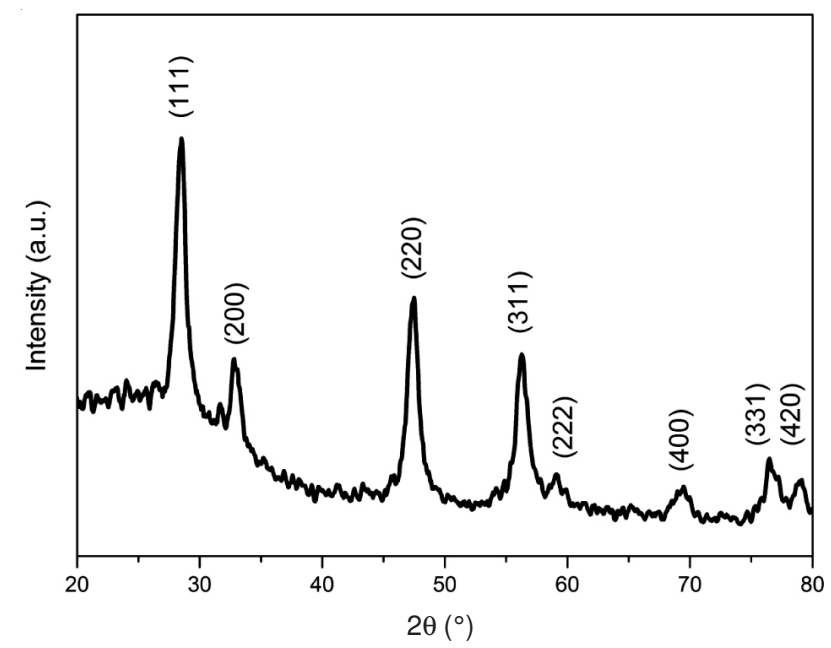

Fig. 1. XRD pattern of as-synthesized $\mathrm{CeO}_{2}$ nanopowders

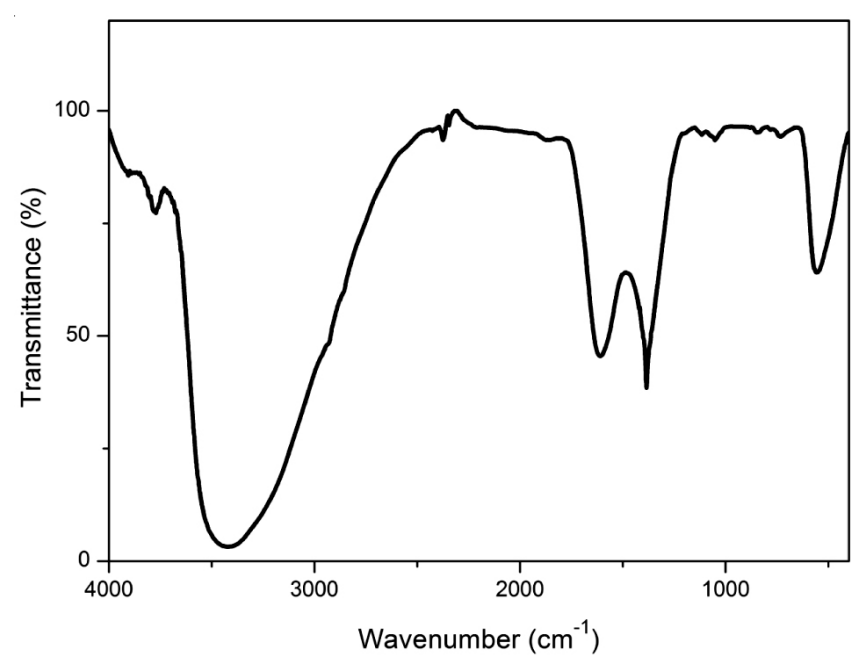

Fig. 2. FT-IR spectrum of as-synthesized $\mathrm{CeO}_{2}$ nanopowders

weaker and the sponge can thus be very easily crumbled, thereby giving rise to small distinct particle aggregates as seen clearly in TEM in Fig. 3(c). It is evident from the TEM image that the particles are smaller in size and uniform spherical in shape. The estimated particle size is around $5 \mathrm{~nm}$. The electron diffraction pattern of the $\mathrm{CeO}_{2}$ nanocrystals consistently matches with the cubic cerium dioxide with fluorite structure confirming high purity and nano-crystallinity. The ring pattern can be indexed to the (111), (200), (220), (311), (222), (400), (331) and (420) planes which are consistent with the peaks observed in the XRD spectrum.
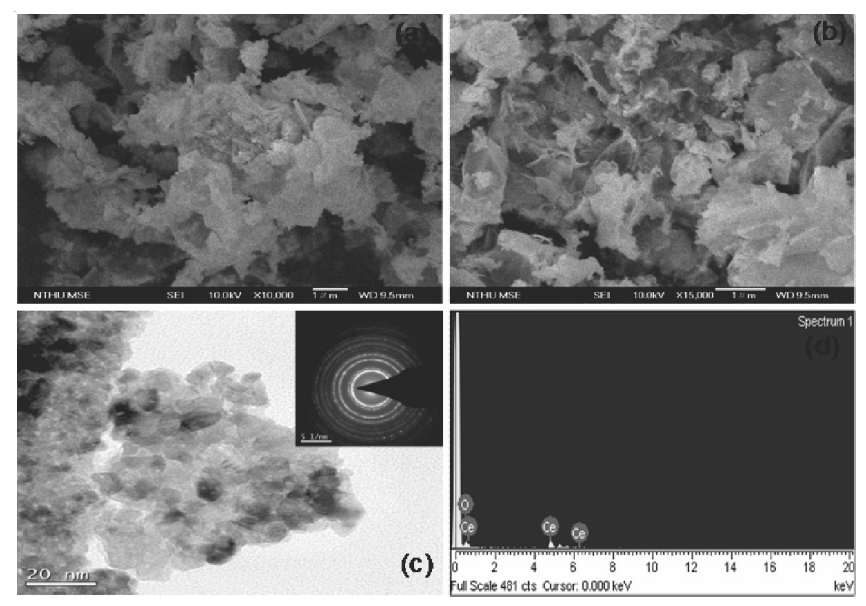

Fig. 3. (a,b) SEM micrograph, (c) TEM image with SAED pattern (shown as insets) and (d) EDX spectrum of pure $\mathrm{CeO}_{2}$ nanoparticles

As observed from the EDX spectrum in Fig. 3(d) there is no impurity content in the as-synthesized product which can be attributed to the fact that the heat released during the combustion reaction is lesser for the fuel lean composition thereby yielding powders without any carbonaceous residue. Moreover, a good amount of oxygen will be available for combustion when fuel deficient composition is used ${ }^{33}$.

Optical characterization: Fig. 4(a) illustrates a typical UV-Visible absorption spectrum of the sample dispersed in ethanol. The absorbance curve of the $\mathrm{CeO}_{2}$ pure sample is composed of one large band, whose maximum is located at around $270 \mathrm{~nm}$. Pure $\mathrm{CeO}_{2}$ distinctly exhibits a strong absorption 
band (below $400 \mathrm{~nm}$ ) at the UV region due to the chargetransfer transitions from $\mathrm{O} 2 \mathrm{p}$ to $\mathrm{Ce} 4 \mathrm{f}$ which overruns the well-known f-f spin-orbit splitting of the Ce $4 \mathrm{f} \operatorname{state}^{34,35}$. As Fig. 4(a) shows most of the UV light (200-350 nm) was blocked by ceria nanoparticles. Therefore, ceria can be used as a UV blocker ${ }^{36}$.
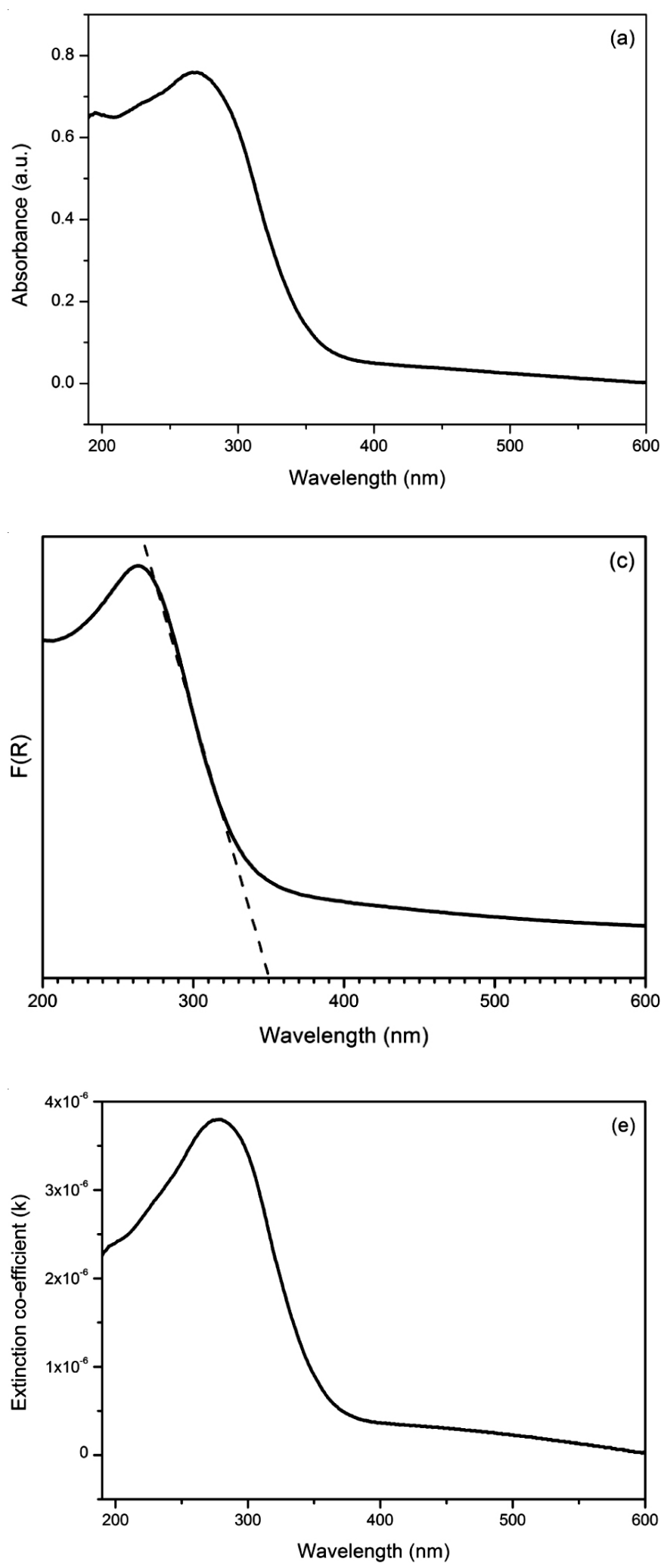

Tauc developed the following equation to calculate the band gap energy.

$$
(\alpha h v)^{n}=B\left(h v-E_{g}\right)
$$

where $\mathrm{E}_{\mathrm{g}}$ is the band gap energy, $\mathrm{B}$ is a constant, hv is the photonic energy, $\mathrm{n}$ is a constant. Plotting $(\alpha \mathrm{h} v)^{2}$ as a function
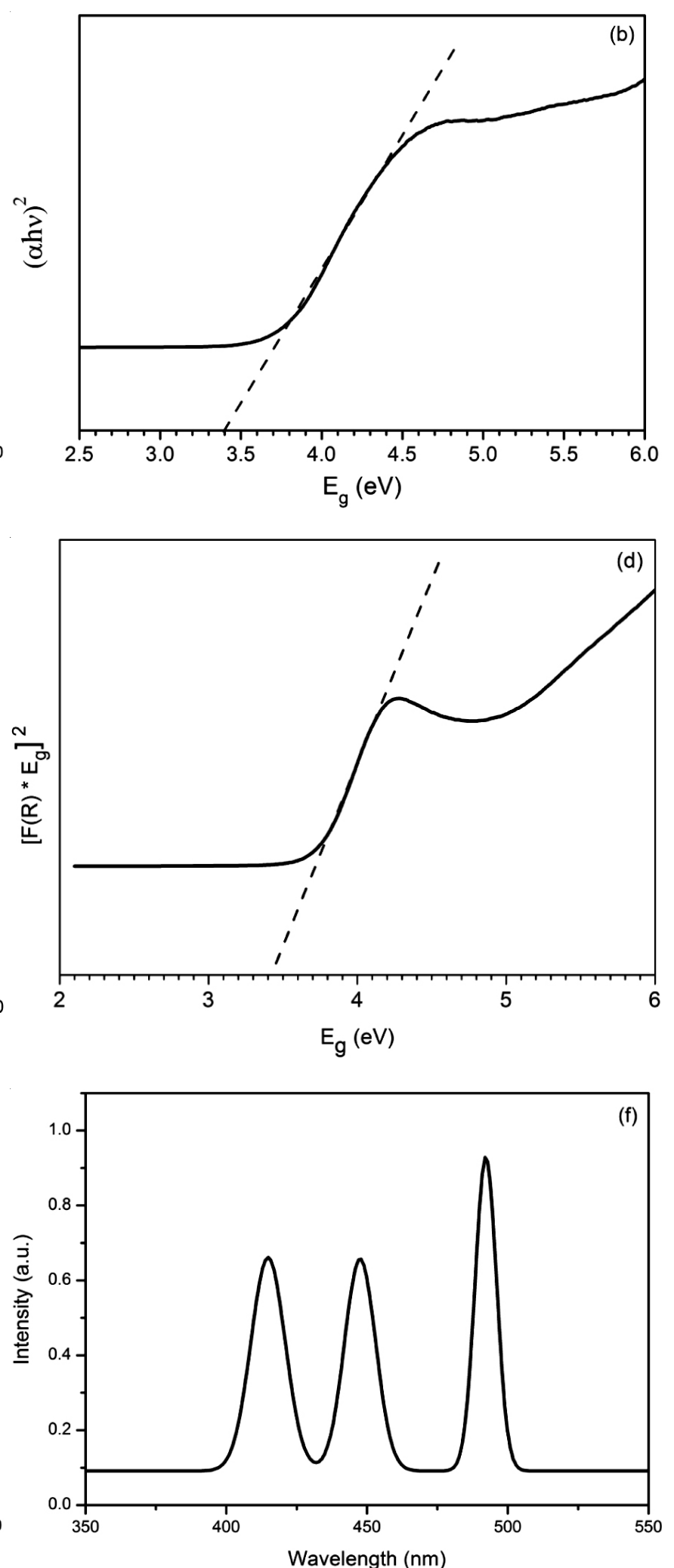

Fig. 4. (a) UV-Visible absorbance spectrum, (b) Tauc plot, (c) Kubelka-Munk function versus wavelength (d) Determination of energy band gap (e) Wavelength dependent extinction co-efficient (k) and (f) photoluminescence spectra of as-prepared pure $\mathrm{CeO}_{2}$ nanoparticles 
of photon energy and extrapolating the linear portion of the curve gives the value of the direct band gap energy. The band gap energy for allowed direct transitions of $\mathrm{CeO}_{2}$ nanoparticles is $3.4 \mathrm{eV}$ as from the Tauc plot in Fig. 4(b). The band gap energies of samples are much greater than that of the bulk which is $3.19 \mathrm{eV}$. As we go from bulk materials to the nanoscale materials, electron energy levels are altered from continuous to discrete levels. Therefore, the radiation from nanoparticles is proposed to be "blue shifted" reflecting the fact that electrons must fall a greater distance in terms of energy and produce radiation of a shorter wavelength ${ }^{37}$. Since the size-related band gap energy of nano-semiconductor can be quantified, it is possible to calculate an optical particle size using the band gap shift measured from absorption spectrum ${ }^{37}$. The relation between the particle size and effective band gap energy of a nanomaterial can be written as:

$$
\mathrm{E}_{\mathrm{g}, \mathrm{n}}=\mathrm{E}_{\mathrm{g}, \mathrm{b}}+\frac{\pi^{2} \mathrm{~h}^{2}}{2 \mathrm{R}^{2}}\left(\frac{1}{\mathrm{~m}_{\mathrm{e}}^{*}}+\frac{1}{\mathrm{~m}_{\mathrm{h}}^{*}}\right)-\frac{1.8 \mathrm{e}^{2}}{\varepsilon \mathrm{R}}
$$

where $E_{g, b}$ and $E_{g, n}$ are the bulk and nanoparticles band gap energies, $\mathrm{R}$ is the particle radius, $\mathrm{m}_{\mathrm{e}}{ }^{*}$ and $\mathrm{m}_{\mathrm{h}}{ }^{*}$ are the effective masses of the electron and hole, respectively which are $m_{e}{ }^{*}=$ $\mathrm{m}_{\mathrm{h}}{ }^{*}=0.4 \mathrm{~m}_{\mathrm{o}}, \mathrm{m}_{\mathrm{o}}$ is the mass of a free electron, $\mathrm{h}$ is Plank's constant and $\varepsilon$ is the bulk optical dielectric constant. When $\mathrm{R}$ is very small (comparable to the Bohr radius), the $1 / \mathrm{R}^{2}$ term is dominant and the band gap energy increases with decreasing $\operatorname{size}^{31}$. The particle size estimated using eqn. 2 is $c a .4 \mathrm{~nm}$.

Another important optical parameter is the extinction co-efficient (k), which can be determined by the formula given below.

$$
\alpha=\frac{4 \pi \mathrm{k}}{\lambda}
$$

where $\alpha$ is the absorption co-efficient and $\lambda$ is the wavelength of the incident light. The plot of extinction co-efficient $(\mathrm{k})$ against wavelength is drawn in Fig. 4(e).

The standard deviation of the band gap energy values is quite small, not exceeding $0.015 \mathrm{eV}$, indicating the good repetition of the UV absorption measurements and the reliability of the band gap energies determined. To test the stability of the colloidal solution measured, the solution was allowed to stand for $24 \mathrm{~h}$. Strikingly, no precipitation took place and the determined value of $\mathrm{E}_{\mathrm{g}}$ remained unchanged. Therefore, the blue-shifting appearing in the UV spectra in the $\mathrm{CeO}_{2}$ nanocrystals indeed was due to the quantum size effect.

The sample was characterized by UV-diffuse reflectance spectroscopy. Fig. 4(c) presents the plot of Kubelka-Munk function against wavelength. Using the Kubelka-Munk function $\mathrm{F}(\mathrm{R})$, the (hv $\mathrm{F}(\mathrm{R}))^{2}$ was plotted against the hv as in Fig. 4(d). Here the unit for hv is $\mathrm{eV}$ and its relationship to the wavelength $\lambda(\mathrm{nm})$ becomes

$$
\mathrm{h} v=\frac{1239.7}{\lambda}
$$

The band gap energy $\mathrm{E}_{\mathrm{g}}$ of ceria nanoparticles is $3.4 \mathrm{eV}$ as obtained by extrapolating the linear portions of the KubelkaMunk function curve in Fig. 4(d) and noting the intercepts with the energy axis.
The Gaussian fit of the room temperature photoluminescence spectra recorded by $327 \mathrm{~nm}$ light excitation is given in Fig. 4(f). Hitherto, limited studies have been reported on photoluminescence study of $\mathrm{CeO}_{2}$ pure systems. The intrinsic defects, such as oxygen vacancies, which act as luminescent centers, can form defect levels located highly in the gap, trapping electrons from the valence band to contribute to the luminescence. The spectrum depicts a strong violet-light emission peak around $415 \mathrm{~nm}$, a blue-band around $448 \mathrm{~nm}$ and a bluish-green emission at $492 \mathrm{~nm}$. The sharp bluish-green emission is due to the density of oxygen vacancies. The results show three photoluminescence peaks that are in good intensity in contrast to earlier reports ${ }^{38-41}$ where one or two emissions are observed. Moreover, it is essential to note that the intensity of violet and blue emission is almost equal and the bluishgreen emission intensity is dominant among the three bands. The emission of these sharp intensity photoluminescence bands can be attributed to the fact that the synthesized nanoparticles posses very small particle size and better crystallinity thereby revealing wide band gap of $3.4 \mathrm{~nm}$ dissimilar to its bulk counterpart due to quantum confinement effect. Cerium dioxide semiconductor nanocrystals with wide direct band gap possess unique optical properties and their emission colour can therefore be tuned across the visible spectrum. This allows optical quantum dot light emitting diodes to create almost any colour. This provides more colour options and better colour rendering than traditional light emitting diodes.

\section{Conclusion}

Combustion synthesis yields pure ultrafine nanocrystals of ceria free of residual carbonaceous matter. The XRD and TEM studies suggest that the average particle size is $5 \mathrm{~nm}$, with cubic fluoride structure. The nanoparticle showed a strong UV-Visible absorption below $400 \mathrm{~nm}$ with a well-defined absorption peak at $270 \mathrm{~nm}$ and the direct band gap was found to be $3.4 \mathrm{eV}$. The band gap determined from UV-DRS by using Kubelka-Munk function was also $3.4 \mathrm{eV}$. The band gap values determined by two different ways concur well with each other. The $\mathrm{CeO}_{2}$ particles also exhibited strong room temperature photoluminescence.

\section{ACKNOWLEDGEMENTS}

The authors thank AICTE, New Delhi, India for financial support rendered through NDF Scheme.

\section{REFERENCES}

1. W. Yuejnan, M. Jingnieng, L. Mengfei, F. Ping and H. Mai, J. Rare Earth, 25, 58 (2007).

2. M.-S. Tsai, Mater. Sci. Eng. B, 110, 132 (2004).

3. T. Mori, Y.R. Wang, J. Drennan, G. Auchterlonie, J.-G. Li and T. Iakegami, Solid State Ionics, 175, 641 (2004).

4. A. Trovarelli, C. deLeitenburg, M. Boaro and G. Dolcetti, Catal. Today, 50, 353 (1999).

5. R.E. Kiork and D.F. Othmer, Encyclopedia of Chemical Technology, Wiley, New York, edn. 3, Vol. 5, p. 315 (1979).

6. R.O. Fuentes and R.T. Baker, Int. J. Hydrogen Energy, 33, 3480 (2008).

7. E. Bekyarova, P. Formasiero, J. Kaspar and M. Graziani, Catal. Today, 45, 179 (1998).

8. N. Izu, W. Shin, N. Murayama and S. Kanzaki, Sens. Actuators B, 87, 95 (2002).

9. S. Tsunekawa, R. Sahara, Y. Kawazoe and A. Kasuya, Mater. Trans. JIM, 41, 1104 (2000). 
10. M. Boaro, M. Vicario, C. De Leitenburg, G. Dolcetti and A. Trovarelli, Catal. Today, 77, 407 (2003).

11. B.R. Powell, R.L. Bloink and C.C. Erckel, J. Am. Ceram. Soc., 71, C104 (1988)

12. N. Hirosaki, A. Okada and K. Matoma, J. Am. Ceram. Soc., 71, C174 (1988).

13. F.F. Lange, J. Mater. Sci., 17, 225 (1982).

14. A.G. Merzhanov, J. Mater. Chem., 14, 1779 (2004).

15. J.J. Moore and H.J. Feng, Prog. Mater. Sci., 39, 243 (1995).

16. J.J. Moore and H.J. Feng, Prog. Mater. Sci., 39, 275 (1995).

17. M.S. Wooldridge, Prog. Energy Combust. Sci., 24, 63 (1998).

18. K.C. Patil, S.T. Aruna and S. Ekambaram, Curr. Opin. Solid State Mater. Sci., 2, 158, (1997).

19. M.P. Pechini, US Patent, 323132825 (1966).

20. R.D. Purohita, S. Sahaa and A.K. Tyagi, Ceram Int., 32, 143 (2006).

21. S.R. Jain, K.C. Adiga and V.R. Pai Venekar, Combust. Flame, 40, 71 (1981).

22. J. Tsay and T. Fang, J. Am. Chem. Soc., 82, 1409 (1999).

23. B.D. Cullity and S.R. Stock, Elements of X-ray Diffraction, Prentice Hall, Upper Saddle River, NJ, edn. 3 (2001).

24. E. Finocchio, M. Daturi, C. Binet, J.C. Lavalley and G. Blanchard, Catal. Today, 52, 53 (1999).

25. T. Wang and D.-C. Sun, Mater. Res. Bull., 43, 1754 (2008).

26. D. Andreescu, E. Matijevic and D.V. Goia, Colloids Surf. A, 291, 93 (2006).

27. J. Liu, Z. Zhao, J. Wang, C. Xu, A. Duan, G. Jiang and Q. Yang, Appl. Catal. B, 84, 185 (2008).
28. M.J. Sun, G.J. Zou, S. Xu and X.L. Wang, Mater. Chem. Phys., 134, 912 (2012).

29. S. Wang, F. Gu, C. Li and H. Cao, J. Cryst. Growth, 307, 386 (2007).

30. S. Phoka, P. Laokul, E. Swatsitang and V. Promarack, Mater. Chem. Phys., 115, 423 (2009).

31. J. Zhang, X. Ju, Z.Y. Wu, T. Liu, T.D. Hu and Y.N. Xie, Chem. Mater, 13, 4192 (2001).

32. S. Samiee and E.K. Goharshadi, Mater. Res. Bull., 47, 1089 (2012).

33. C.-C. Hwang, T.-H. Huang, J.-S. Tsai, C.-S. Lin and C.-H. Peng, Mater. Sci. Eng. B, 132, 229 (2006).

34. P. Patsalas and S. Logothetidis, Phys. Rev. B, 68, 035104 (2003).

35. R.T. Kuphaldt, Lessons in Electric Circuits, Semiconductors, Vol. 3, edn. 5 (2009).

36. M. Yamashita, K. Kameyama, S. Yabe, S. Yoshida, Y. Fujishiro, T. Kawai and T. Sato, J. Mater. Sci., 37, 683 (2002).

37. J.J. Miao, H. Wang, Y.R. Li, J.M. Zhu and J.J. Zhu, J. Cryst. Growth., 281, 525 (2005).

38. S. Maensiri, C. Masingboon, P. Laokul, W. Jareonboon, V. Promarak, P.L. Anderson and S. Seraphin, Cryst. Growth. Des., 7, 950 (2007).

39. S. Sathyamurthy, K.J. Leonard, R.T. Dabestani and M.P. Paranthaman, Nanotechnology, 16, 1960 (2005).

40. S.H. Yu, H. Cölfen and A. Fischer, Colloid. Surf. A, 243, 49 (2004).

41. M.G. Sujana, K.K. Chattopadyay and S. Anand, Appl. Surf. Sci., 254, 7405 (2008). 